\title{
MAKNA RITUAL MARARI SABTU PADA RUAS UGAMO MALIM
}

\author{
Agung Suharyanto ${ }^{1)}$, Agnes E. Sianipar ${ }^{2)}$, Chia-chia Fonda ${ }^{2)}$, Debora P. \\ Pasaribu $^{2)}$, Dini Rizkiana Putri ${ }^{2)}$, Dwi Kesuma Ningrum ${ }^{2)}$, Eka Mairani ${ }^{2} \&$ \\ Fitri Ramayana ${ }^{2)}$ \\ 1) Program Studi Ilmu Pemerintahan, Fakultas Ilmu Sosial dan Ilmu Politik \\ Universitas Medan Area, Indonesia \\ 2) Program Studi Pendidikan Antropologi, Fakultas Ilmu Sosial \\ Universitas Negeri Medan, Indonesia
}

\begin{abstract}
Abstrak
Penelitian ini bertujuan untuk mengetahui proses ritual, komponen dan makna serta fungsi dari ritual Marari Sabtu yang dilakukan Agama Parmalim. Metode yang digunakan adalah kualitatif yang dilakukan secara langsung di Jalan Seksama tepatnya di Gang Rela No. 15 Medan Kelurahan Binjai Kecamatan Medan Denai dengan teknik observasi dan wawancara. Hasil penelitian didapatkan bahwa proses Mararisabtu merupakan suatu kegiatan rutin yang di lakukan oleh para jemaat agama Parmalim untuk melakukan pemujaan terhadap mula jadi nabolon. Terdapat berbagai komponen yang digunakan dalam upacara yaitu terdapat berbagai benda yang di gunakan berupa dupa, jeruk purut, kurukuru, kemenyan, air yang di ambil sebelum ayam berkokok, serta tikar ayaman tempat ulu punguan. Makna dan fungsi dari ritual marari sabtu yaitu untuk memanjatkan doa kepada mula jadi nabolonagar di beri kesehatan, keselamatan, keamanan, dan kemakmuran. Setiap hari Sabtu atau Samisara seluruh umat Parmalim berkumpul di tempat yang sudah ditentukan baik si Bale Partonggoan, Bale Pasogit di pusat maupun di rumah parsantian di cabang/daerah untuk melakukan sembah dan puji kepada Mulajadi Nabolon dan pada kesempatan itu para anggota diberi poda atau bimbingan agar lebih tekun berprilaku menghayati Ugamonya.
\end{abstract}

Kata kunci : Parmalim, Marari Sabtu,Ritual. 


\begin{abstract}
This study aims to determine the ritual process, components and the meaning and function of the Saturday Marari ritual carried out by the Parmalim Religion. The method used is qualitative conducted directly on Jalan Seksama precisely in Gang Rela No. 15 Medan Binjai Village Medan District Denai with observation and interview techniques. The results showed that the Mararis process was a routine activity carried out by the parishioners of the Parmalim religion to worship the origin of being nabolon. There are various components used in the ceremony, there are various objects that are used in the form of incense, kaffir lime, kurukuru, incense, water taken before the rooster crows, as well as ayaman mats where ulu punguan. The meaning and function of the Saturday marari ritual is to say a prayer to the beginning of being nabolonagar given health, safety, security, and prosperity. Every Saturday or Samisara all Parmalim congregations gather in a designated place, either Bale Partonggoan, Bale Pasogit at the center or at the parade house in the branch / area to worship and praise Mulajadi Nabolon and on that occasion the members are given a more diligently behaving to live his Ugandan.
\end{abstract}

Keywords: Parmalim, Marari Saturday, Ritual 


\section{Pendahuluan}

Masyarakat Indonesia adalah masyarakat yang memiliki tradisi keberagamaan yang sangat plural, tidak hanya agama mainstream yang terlembaga, tetapi juga kepercayaan lokal tetap bertahan sampai kini (Sugiyarto W \& Asnawati, 2012). Menurut Hasbullah (2012), agama adalah keyakinann yang mana tidak dapat di pisahkan oleh individu yang memeluknya. Keyakinan yang dianut oleh setiap individu sudah melekat dari nenek moyang masyarakat terdahulu dimana sekarang diasosiasikan secara turun-temurun selama masyarakat itu tetap ada. Agama adalah sebuah realitas yang tidak dapat di ganggu gugat oleh siapa pun, baik itu dari masyarakat tradisional maupun masyarakat modern.

Keberadaan kepercayaan lokal di Indonesia sebenarnya telah ada sejak dulu, bahkan sebelum adanya agama-agama yang masuk di Indonesia yang sekarang telah diakui oleh pemerintah sebagai agama resmi di Indonesia. Sampai saat ini, kepercayaan lokal masih ada, seperti Parmalim yang ada pada etnis Batak Toba, meskipun keberadaan kelompok yang menganut kepercayaan lokal tersebut perlahan-lahan telah berkurang. Kepercayaan ini juga tidak hanya tersebar di Toba Samosir saja, meski asal mulanya berasal dari Toba Samosir, juga sudah tersebar di beberapa kota besar di Indonesia, salah satunya adalah di Kota Medan di Jalan Seksama gang rela no. 15 Medan.

Parmalim secara antropologis disebut sebagai agama yang diturunkan oleh Tuhan (Debata Mulajadi Nabolon) khusus kepada suku Batak. Debata Mulajadi Nabolon adalah pencipta, sekaligus pemilik alam semesta alam. Orang yang menjadi utusan Debata Mulajadi Nabolon adalah sisingamagaraja XII si Raja Batak(Sugiyarto\& Asnawati, 2012). Penelitian ini dilakukan karena adanya rasa penasaran terhadap kepercayaan lokal yang ada di Kota Medan. Agama Parmalim menjadi subjek pada penelitian kali ini, Parmalim merupakan salah satu kepercayaan lokal yang masih terlihat eksistensinya di Kota Medan. Agama Parmalim yang masih ada saat ini sudah tidak banyak yang menganutnya ditengah perkembangan zaman yang semakin mengikis, penganut agama Parmalim masih bertahan. Parmalim adalah salah satu nama penganut kepercayaan lokal yang ada di provinsi Sumatera Utara pada suku Batak Toba. 
Agama Parmalim sudah ada di Indonesia sebelum agama lain datang dan menetap di Indonesia. Misalnya agama Islam, Budha, Hindu, Kristen dan Konghucu yang telah menetap dan berkembang hingga saat ini. Kelima agama tersebut lebih pesat pertumbuhan dan perkembangannya jika dibandingkan dengan agama lokal. Banyak agama lokal yang masih dianut dibeberapa provinsi di Indonesia, diantaranya yakni Sumatera Utara (Pemena dan Habonaran Do Bona), Kalimantan (Kaharingan), Jawa Barat (Baduy) dan daerah lainnya.

Munculnya agama Parmalim, pada ratusan tahun yang lalu sebelum masuknya agama Islam dan Kristen masuk ke tanah Batak dan saat agama Malim resmi ada, kepercayaan dan ajaran keagamaam Batak sesungguhnya sudah mulai ada (Gultom, 2010). Dimana menurut kepercayaan Agama Malim, ajaran keagamaan itu dibawa oleh perintah atau utusan Debata Mula jadi Nabolon.suruhan Debata yang membawa ajaran kepercayaan itu dinamakan Malim Debata (Suharyanto, 2016). Agama Parmalim berkedudukan di desa Pardomuan Nauli Hutatinggi, Kecamatan Laguboti, Kabupaten Toba Samosir sebagai pusat administrasi agama malim dan memiliki 48 cabang yang tersebar di seluruh Indonesia. 18 diantaranya berada di Provinsi Sumatera Utara, salah satu di Kota Medan tepatnya di jalan Seksama/M. Nawi Harahap Gang Rela No.15 yang merupakan Sekretariat Himpunan Penghayat Kepercayaan Terhadap Tuhan Yang Maha Esa Sumatera Utara dan Sekretariat Ugamo Malim untuk cabang wilayah kota Medan. Sehingga penulis menetapkan sebagai lokasi dalam perolehan sumber data.Jumlah pengikut agama Parmalim lebih dari 1.500 keluarga atau pun sekitar 6.00 jiwa (Corry, 2015). Dengan demikian, apabila dilihat, maka masih banyak terdapat orang batak toba yang masih mempertahankan agama lokal mereka.

Agama Parmalim juga sangat ketat menjaga adat istiadatnya, hal ini dikarenakan, kebudayaan Batak sudah menjadi patron didalam kehidupan seharihari, sekaligus panduan spiritual. Dalam kesungguhannya untuk menjaga dan merawat keseluruhan budaya yang telah diwariskan nenek moyang, merka menjalankan dalam kehidupan sehari-hari dan ritual peribadatannya. Salah satunya adanya Gondang dan Manorotor yang menjadi bagian dalam upacara 
ibadah dan ritual pada setiap ruas Penganut Parmalim (Suharyanto, 2011) (Suharyanto, 2012), (Suharyanto, 2014).

Penganut Parmalim menyebutnya sebagai Ugamo Malim yang mana merupakan agama asli suku Batak Toba dan ini merupakan kelanjutan agama lama (Situmorang, 1993) (Gultom, 2010). Ugamo Malim tidak hanya merasuk dalam bagian kehidupan sehari-hari, akan tetapi juga sebagai panduan ritual peribadatannya dalam beberapa pesta adat (ulaon).

Adapun aturan ajaran Ugamo Malim terdiri dari tujuh bagian yaitu: 1)Marari Sabtu, yaitu hari ibadah yang dilakukan setiap hari sabtu; 2) Martutu Aek, yaitu penabalan atau pembuatan nama pada bayi yang baru lahir; 3) Mardebata, yaitu pengucapan syukur dan pengampunan dosa kepada yang kuasa; 4) Pasahat Tondi, yaituritual 30 hari setelah kematian; 5) Mangan Napaet, yaitu puasa yang dilakukan selama 24 jam; 6) Sipaha Sada, yaitu hari kelahiran Tuhan Simarimbulubosi; 7) Sipaha Lima, yaitu ritual pengucapan syukur atas hasil panen (Siahaan, 2018) (Gultom, 2010).

Ugamo Malim berpatokan pada tiga debata yaitu Debata Natolu, Debata Sorisohaliapan, dan Debata Belabuhan. Dimana ajaran tersebut kemudian diturunkan kepada tokoh-tokoh adat atau raja-raja pada masa dulu. Raja bagi bangsa Batak dulu dianggap sebagai jelmaan Debata sehingga masyarakat Batak sangat percaya kepada titah raja. Dimana ajaran tersebut kemudian diturunkan kepada tokoh-tokoh adat atau raja-raja pada masa dulu. Raja bagi bangsa Batak dulu dianggap sebagai jelmaan Debata sehingga masyarakat Batak sangat percaya kepada titah raja (Suharyanto, 2016).

Dari uraian di atas, Parmalim bisa dikaitkan dengan sistem yang melekat pada masyarakat tersebut, yaitu apabila dikaitkan dengan defenisi agama oleh Clifford Geertz (1973), yang menyatakan bahwa, “Agama sebagai sebuah system budaya berawal dari sebuah kalimat tunggal yang mendefinisikan agama sebagai: 1) Sebuah sistem simbol yang bertujuan; 2) Membangun suasana hati dan motivasi yang kuat, mudah menyebar dan tidak mudah hilang dalam diri seseorang dengan cara; 3) Merumuskan tatanan konsepsi kehidupan yang umum; 4) Melekatkan konsepsi tersebut pada pancaran yang factual; 5) Yang pada akhirnya konsepsi tersebut akan terlihat sebagai suatu realitas yang unik. 
Defenisi di atas, akan dapat menjawab beberapa pertanyaan yang lebih banyak lagi tentang Ugamo Malim, agar nantinya tidak timbul suatu kesalahan dalam penafsiran yang terkait dengan ritual peribadatan yang dijalankan oleh para pengikutnya. Ugamo Malim dalam melakukan suatu peribadatan dengan tujuan agar hidupnya tercapai dan memiliki keberkahan. Dapat menenangkan hati, pikiran, perasaan saat melakukan peribadatan agar tidak adanya suatu permasalahan yang buruk dan dengan keadaan yang damai. Dengan berbagai cara dan aturan yang di lakukan, untuk mencapai suatu tujuan tersebut melalui tahap yang telah di buat. Salah satu peribadatan yang menjadi fokus dalam penelitian ini adalah Marari Sabtu.

Marari Sabtu memiliki keunikan tersendiri yaitu pada setiap hari Sabtu atau Samisara seluruh umat Parmalim berkumpul di tempat yang sudah ditentukan baik si Bale Partonggoan, Bale Pasogit di pusat maupun di rumah parsantian di cabang/daerah untuk melakukan sembah dan puji kepada Mulajadi Nabolon dan pada kesempatan itu para anggota diberi poda atau bimbingan agar lebih tekun berperilaku menghayati Ugamonya. Disini mereka melakukan penyembahan dan pujian kepada Mulajadi Nabolon dengan cara-cara yang telah dipercayai. Dalam pelaksanaan rangkaian marari sabtu, ada semacam diskusi atau sharing yang dilakukan satu dengan yang lain sesama ruas, mencari solusi bersama setiap permasalahan dan melakukan makan bersama. Bukti kekompakan dan persatuan ugamo Parmalim yang diteliti sehingga terlihat unik dan menarik untuk mengkajinya.

\section{Metode Penelitian}

Penelitian ini dilakukan di Jalan Seksama tepatnya di Gang Rela No. 15 Medan Kelurahan Binjai Kecamatan Medan Denai. Lokasi penelitian ini merupakan salah satu lokasi tempat peribadaan Ruas Ugamo Malim (Majelis Luhur Kepercayaan Terhadap Tuhan Yang Maha Esa). Fokus penelitian ini, mengenai Makna, fungsi dan komponen dari peribadatan agama Parmalim pada Marari Sabtu yang dilakukan Parmalim di Punguan Gang Rela.

Metode penelitian yang digunakan adalah metode penelitian deskriptif yang bersifat kualitatif dengan menggambarkan ataupun mendeskripsikan mulai dari awal ibadah sampai berakhirnnya peribadatan, Makna, fungsi dan komponen 
dari peribadatan agama Parmalim pada Marari Sabtu. Observasi dilakukan secara langsung di rumah peribadatan agama Parmalim ini, dari mereka sebelum menjalanakan peribadatan, melihat mereka menjalankan aturan-aturan yang harus di patuhi oleh setiap ruas (umat) Parmalim. Melihat tata cara aturan berpakaian bagi perempuan dan pria memiliki perbedaan untuk yang sudah menikah dan belum menikah. Kaum perempuan mereka menggunakan ulos dan kain sarung dan membuat bersanggul Toba. Para laki-laki memakai surban putih (tali-tali) dan kain sarung dan ulos bagi yang sudah menikah. Selain itu terdapat berbagai komponen upacara yang dipakai dalam peribadatan di dalam ruang ibadah.

Untuk mendapatkan data yang lebih akurat, selain mengadakan penelitian secara langsung di Lapangan, juga dilakukan dengan mencari beberapa referensi, salah satunya adalah artikel di jurnal yang kami relevan. Jurnal ini diambil untuk memperkuat data yang kali peroleh di lapangan, yaitu sebuah jurnal dengan judul "Eksistensi agama lokal Parmalim dimana studi kasus yang di lakukan dalam jurnal ini berda di Nomonatif penghayat nomor Punguan35 Desa Air Kulim Mandau Bengkalis, oleh Nelita (2017) dan Suharyanto (2016), Pusat Aktivitas Ritual Ugamo Malim di Huta Tinggi Laguboti Toba Samosir .Jurnal Ilmu Pemerintahan dan Sosial Politik UMA: 182-195.Dalam artikel penelitian tersebut, terdapat bagian mengenai marari sabtu, yang dapat digunakan sebagai litertur untuk memperkuat data yang diperoleh di lapangan. Selain itu juga ada beberapa buku referensi, seperti Agama Malim di Tanah Batak (Gultom, 2010) yang juga menguraikan secara detai mengenai Ritual Ugamo Malim.

Pada saat melakukan penelitian, dokumentasi foto dilakukan pada saat awal acara, hingga akhir acara peribadatan, juga dalam beberapa sesi wawancara dengan narasumber di lokasi peelitian. Audio visual juga dipakai untuk mendokumentasikan acara ibadah pada agama Parmalim, yang sebelumnya sudah meminta ijin kepada Ulu Punguan. Selain itu peneliti juga menggunakan catatancatatan secara manual untuk mencatat hal-hal penting dari informan sebagai sumber informasi bagi peneliti. Setiap pertanyaan yang ditanyakan, secara bururut dan bahkan juga seperti obrolan yang santai dilakukan untuk mendapatkan jawaban yang baik. 
Wawancara merupakan sebuah pertemuan antara dua orang untuk bertukar informasi dan ide melalui tanggang jawab, sehingga dapat di konstruksikan makna dalam suatu topik tertentu (Esterbeg dalam Sugiyono, 2013). Wawancara langsung dilakukan setelah usai peribadatan kepada para panatua yang berada di rumah ibadah tersebut, yaitu Bapak Togi M Sirait yang menyambut kami dengan penuh ramah. Dalam sesi wawancara yang dilakukan setelah selesai peribadatan, semua jemaat (ruas) berkumpul di Pungun ini, semua pertanyaan dijawab secara bersamaan dan bergantian oleh semua jemaat.

Teknik analisis data adalah kegiatan analisis dalam penelitian yang dilakukan dengan menelaah seluruh data yang tersedia dari instrumen penelitian,yang terdiri dari catatan, rekaman, dokumen dan lainnya (Moleong, 2007). Penelitian ini, melakukan analisis data pada komponen, makna dan fungsi serta tata urutan upacara peribadatan pada Agama Parmalim.

\section{Hasil Dan Pembahasan}

\section{Tata Urutan UpacaraMarari Sabtu}

Upacara Marari Sabtu, pada setiap hari Sabtu atau Samisara oleh seluruh Ruas (umat/jemaat) Parmalim berkumpul di tempat ibadah yang ada di rumah jalan Rela untuk melakukan sembah dan puji kepada Mulajadi Nabolon. Satu persatu ruas Parmalim memasuki rumah ibadahnya dan duduk dengan tekun untuk mengikuti jalannya upacara. Ruangan yang digunakan Nampak sudah tertata rapi, seperti terletak air penyucian (aek pangurason) yang airnya diambil terlebih dahulu dari sumber air dan sudah dimasukkan kedalam ceret dan mangkuk (cawan) putih berisi jeruk purut (anggir) dan daun bane-bane. Alat pembakaran dupa dan peralatan lainnya, juga disiapkan di dekat sebuah meja yang ada di sudut untuk meletakkannya. Jeruk purut (anggir) yang sudah dibelah dicampur dengan air yang sudah disiapkan dalam ceret dan sebagian ke mangkuk putih (cawan) dan daun bane-bane). Daun tersebut akan digunakan mamippis (memercikkan) air tersebut kepada semua peserta upacara.

Pukul 10.30 wib upacara dimulai. Ulu Punguan (pemimpin upacara) memasuki ruangan dan diikuti oleh seluruh peserta upacara dan duduk bersila secara tertib dan rapi. Dalam kepercayaan ini, pemimpin agamanya disebut Ihutan Bolon. Orang yang mewakili penganut dari setiap daerah disebut Ulupunguan. 
Ihutan bertanggung jawab atas pelaksanaan upacata keagamaan. Dia memimpin doa atau disebut juga dengan tonggo-tonggo dalam upacara keagamaan Parmalim.

Air dalam mangkuk putih harus sudah ada dalam Parsantian di atas tikar (lage tiar) yang berlapis tiga. Saat jemaat (ruas) Parmalim masuk kedalam ruang ibadah, mereka berdoa dulu sebelum memulai ibadat. Ini diharapakan mereka mendapatkan berkat dari Ompu Mula Jadi Na Bolon. Setelah itu mereka duduk dengan tempat duduk yang terpisah, perempuan di sebelah kanan dan laki-laki disebelah kiri. Dan setiap doa dilakukan setelah semua duduk. Selain itu laki-laki yang sudah menikah mengenakan sorban di kepala, juga sarung dan selendang batak (ulos). Sementara yang perempuan memakai sarung, juga memakaiu konde serta menyanggul rambut mereka, dari konde perempuan laki-laki menilai apakah perempuan itu rapi atau tidaknya.

Semua ruas (Jemaat atau umat) Parmalim, memfokuskan pikiran (berkonsentrasi) untuk mengikuti ritus demi ritus dalam upacara. Setelah semua tertib, Ulu Punguan melafalkan tonggo-tonggo (Doa-doa) sedangkan ruas (jemaat/umat) menyimaknya. Doa-doa yang digunakan tersebut ialah:(1) Doa untuk Mulajadi Nabolon, Tuhan Pencipta langit dan bumi; Doa untuk Debata Natolu, (Batara Guru, Debata sori, dan Bala Bulan); Doa untuk Siboru Deak Parujar, yang memberi sumber pengetahuan dan keturunan; Doa untuk Naga Padoha Niaji, penguasa di dalam tanah; Doa untuk Saniang Naga Laut, penguasa air dan kesuburan; Doa untuk Raja Uti yang diutus Tuhan sebagai perantara pertama bagi manusia (Batak); Doa untuk Tuhan Simarimbulu Bosi yang hari kelahirannya sekaligus menjadi momentum perayaan Sipaha Sada; Doa untuk Raja Naopat Puluh Opat yakni semua nabi yang diutus Tuhan kepada bangsabangsa melalui agama-agama tertentu, termasuk Sisingamangaraja yang diutus bagi orang Batak; Doa untuk Raja Sisingamangaraja, raja yang pernah bertahta di negeri Bakkara; Doa untuk Raja Nasiak Bagi, yang dianggap sebagai inkarnasi Raja Sisingamangaraja (Patuan Raja Malim).

Setelah semua urutan tonggo-tongo selesai dipanjatkan, kemudian Ulu Punguan memaparkan isi patik dengan menghadap kepada peserta (layaknya orang yang berceramah). Setelah itu dilakukan siraman rohani yang diawali oleh satu atau dua orang dari peserta dan kemudian disimpulkan (panippuli) oleh Ulu 
Punguan. Setelah sesi ini selesai, kemudian diakhiri doa bersama dan kemudian sang Ulu Punguan mengambil aek pangurason dan memercik-mercikkannya ke para ruas. Setelah itu, dua orang muda-mudi mengambil ceret dan gelas kecil yang sudah tersedia menuangkan air ke gelas lalu membagi-bagikannya untuk di minum dengan doa tertentu yang mereka percayai.

\section{Komponen Upacara Keagamaan}

Pada pelaksanaan upacara Keagamaan ini peneliti turun ke lapangan dimana kami melakukan penelitian mengenai agama Parmalim ini di Jalan Seksama tepatnya di Gang Rela No.15 Medan lokasi yang merupakan tempat peribadaan agama Malim yang merupakan rumah dan sekaligus di tempati menjadi tempat tinggal, sehingga tempatnya juga berbeda dengan yang ada di Hutatinggi Laguboti. Jika di Hutatinggi Laguboti, tempat upacara disebut Bale Pasogit, diseberangnya ada bangunan yang bernama bale Parpitaan, yaitu tempat untuk mengugamohon atau tempat untuk meniatkan sajian (pelean) yang hendak dipersembahkan oleh Ihutan. Ada juga namanya bale Pangaminan ini juga merupakan tempat untuk perkumpulan para umat (ruas) Ugamo Malim dan dapat ditempati untuk menjadi tempat tinggal selama melaksanakan upacara di Huta Tinggi Laguboti.

Dalam upacara ini, laki-laki yang telah menikah biasanya mengunakan pakaian jas, bersorban seperti layaknya orang muslim yang dinamakan tali-tali, sarung dan Ulos (selendang Batak). Sementara yang wanitanya bersarung dan menyanggul rambut mereka dengan bentuk sanggul Toba yang merupakan ciri khas suku Batak Toba. Jika pemuda/pemudi (naposo), dalam mengikuti upacara berpakaian biasa dan memakai sarung biasa serta memakai ulos saja.

Dalam melakukan ritual ibadah Marari Sabtu,ruas (jemaat atau umat) Parmalim menyiapkan berbagai macam bahan sebagai alat persembahan yaitu berupa: Dupa; Jeruk purut (anggir); Daun bane bane; Kemenyan; Ceret, cawan, Air yang diambil sebelum ayam berkokok; dan tikar pandan. Alat-alat ini biasa disiapkan sebelum melaksanakan peribadatan. Dalam melakukan ritual untuk nenek monyangnya terlebih lagi untuk penyembahan kepada Mula Jadi Nabolon. Terdapat berbagai Benda yang di gunkan dalam prosesi ibadah Parmalim yaitu ada: (1) Jeruk Purut (anggir) yang bagi mereka dipercaya dapat menyembuhkan 
segala penyakit dan menyucikan setiap pribadi jemaat (ruas Parmalim, (2) Kemenyan yang dipercaya sebagai salah satu jalan untuk bertemu dengan Ompu Mula Jadi Na Bolo.

Komponen yang sangat penting dalam ibadah Marai Sabtu ini adalah ulu punguan (Pemimpin Perkumpulan) dan ruas (jemaat/umat) Parmalim. Semua ruas (Jemaat atau umat) Parmalim, memfokuskan pikiran (berkonsentrasi) untuk mengikuti ritus demi ritus dalam upacara. Setelah semua tertib, Ulu Punguan akanmelafalkan tonggo-tonggo (Doa-doa), memberikan ceramah dan menyimpulkan ibadah hari ini. Ruas (jemaat/umat) akan mengikuti secara khusus setiap pembacaan tonggo-tonggo, menyimak khotbah dan memberikan masukan tambahan untuk beberapa hal yang penting untuk dilakukan dan dihindari dalam kehidupan.

\section{Fungsi Dan Makna}

Setiap peribadahan yang dilakukan oleh setiap agama, pasti akan memiliki Makna dan Fungsi. Begitu juga dengan agama Parmalim. Pada agama Parmalim ini, terdapat beberapa Makna dan Fungsi dari setiap ibadah yang mereka lakukan yaitu: Sebelum melaksanakan ibadah, setiap umat harus menggunakan pakaian yang rapi. Untuk pakaian sendiri, setiap umut, menggunakan pakaian yang hampir sama antara perempuan dan laki-laki. Untuk laki-laki sendiri, semua harus menggunakan Sarung, serta memakai ulos. Selain itu, bagi laki-laki yang sudah menikah, maka akan memakai sorban di kepala. Sedangkan untuk yang belum menikah, tidak menggunakan kain sorban.

Selain itu, bagi perempuan, menggunakan Sarung, serta memakai ulos. Bagi perempuan, mereka menyanggul rambutnya yang di sebut dengan sanggu toba. Selain itu, bagi yang sudah menikah, mereka akan mengenakan kebaya. Makna dan fungsi dari pakaian mereka ini yaitu, agar mereka lebih rapi serta lebih terlihat besih ketika menghadap Tuhan Yang Maha Esa. Saat berlangsungnya acara, pemimpin ibadah akan memberikan sebuah Khotbah, maknah ini dimaksudkan agar setiap umat dapat mengerti lebih dalam tentang setiap topik dalam peribadahan mereka. Selain itu juga fungsinya yaitu agar mereka lebih dekat dengan tuhan. 
Pada upacara ini, pemimpin ibadah duduk di atas tiar purun ataupun (Tikar anyaman) dimana terdapat tiga lapisan dimana setiap lapisan ini, memiliki makna dan fungsi. Pada lapisan pertama, tikar ini tidak di dudukin. Dimana tikar ini bagi kepercayaan mereka, bahwa tikar pertama ini untuk Naposo Bolon. Sedangkan tikar kedua ini, di gunakan untuk tempat sesembahan dimana terdapat kemenyan yang dibakar dan terdapat mangkuk yang diisi air, daun kemangi serta jeruk purut.

Dalam hal ini, kemenyan memiliki fungsi dan makna untuk mendatangkan roh leluhur mereka serta daun kemangi, jeruk purut serta air berfungsi sebagai air pembersih atau air pemberkatan. Dengan makna agar terberkatilah acara mereka ini. Dan pada lapisan terakhir inilah tempat pemimpin duduk. Dimana pada tikar memiliki fungsi dan makna sebagai tempat yang sangat suci yang tidak semua orang duduk disini.

Selain itu, dalam upacara ketika pemimpin selesai khotbah, maka akan ada dari setiap perwakilan dari Remaja (Naposo), Bapak-bapak serta Ibu-ibu untuk menyampaikan makna dari setiap khotbah yang di berikan. Selain itu, ketika selesai acara, maka dua orang remaja akan memberikan air suci, yang di ambil sebelum ayam bekokok, yang di letakkan di dalam ceret yang berwarna emas. Air ini disebut dengan Air Suci. Dimana air ini memilki makna dan fungsi sebagai bentuk pensucian diri untuk setiap umat yang dimana air ini akan di minim setiap umat. Selain itu, pemimpin akan memercikkan air yang berisi air, jeruk purut serta daun kemangi. Diamna makna air yang di percikkan ini yaitu sebagai air suci ataupun pembersihan jika terdapat suatu penyakit.

Marari Sabtu (peribadatan setiap hari sabtu), yaitu pada setiap hari Sabtu atau Samisara seluruh umat Parmalim berkumpul di tempat yang sudah yang sudah ditentukan baik si Bale Partonggoan, Bale Pasogit di pusat maupun di rumah parsantian di cabang/daerah untuk melakukan sembah dan puji kepada Debata Mula jadi Nabolon dan pada kesempatan itu para anggota diberi poda atau bimbingan agar lebih tekun berprilaku menghayati Ugamonya.

Upacara Marari Sabtu dilakukan dengan tujuan untuk menyucikan diri dari dosa-dosa terlebih dosa yang dilakukan dalam seminggu yang baru dilewati dan untuk membersihkan diri dari segala penyakit. Dengan kata lain untuk menyempurnakan batin. Menurut Wongso Negoro (Ilyas dan Imam, 1988:11) 
kebaktian adalah bentuk kebaktian kepada Tuhan Yang Maha Esa menuju tercapainya budi luhur dan kesempurnaan hidup. Disisi lain Ilyas dan Imam (1988:11) mengatakan bahwa penganut kepercayaan merupakan paham yang bersifat dogmatis yang terjalin dalam adat-istiadat hidup sehari-hari dan berbagai suku bangsa yang adat nenek moyang.

Saat melakukan peribatan agama Malim menyampaikan doa - doa dalam bahasa Batak yang dimana tidak semua dapat peneliti artikan. Namun pada saat melakukan wawancara peneliti menanyakan tentang makna dan fungsi yang disampai selama melakukan ibadah. Panatua tersebut mengatakan mereka memanjatkan doa kepada Debata Mula Jadi Nabolon tentang permohonan atau keinginan. Dimana setiap peribatan selalu memanjatkan doa agar semua hidup aman, damai, dan tentram. Bukan hanya untuk agama malim namun untuk negara ini juga. Dari sifatnya ajaran agama Malim ini berupa poda (nasihat) tona (ajakan)dan tokka (larangan).

\section{Simpulan}

Parmalim adalah salah satu kepercayaan lokal yang ada di provinsi Sumatera Utara pada suku Batak Toba. Dan dimana dalam ugamo malim melakukan marari sabtu yaitu peribadatan yang dilakukan setiap hari sabtu. Proses ritual Marari Sabtu yang berlagsung pada agama Parmalim memiliki keunikan tersendiri yaitu pada setiap hari Sabtu atau Samisara seluruh umat Parmalim berkumpul di tempat yang sudah ditentukan baik si Bale Partonggoan, Bale Pasogit di pusat maupun di rumah parsantian di cabang/daerah untuk melakukan sembah dan puji kepada Mulajadi Nabolon dan pada kesempatan itu para anggota diberi poda atau bimbingan agar lebih tekun berprilaku menghayati Ugamonya. Disini mereka melakukan penyembahan dan pujian kepada Mulajadi Nabolon dengan cara-cara yang telah di percayai mereka.

Marari Sabtu merupakan suatu kegiatan rutin yang di lakukan oleh para jemaat agama Parmalim untuk melakukan pemujaan terhadap mula jadi nabolon. Terdapat berbagai komponen yang digunakan dalam upacara yaitu terdapat berbagai benda yang di gunakan berupa dupa, jeruk purut, bane-bane, kemenyan, air yang di ambil sebelum ayam berkokok, serta tikar ayaman tempat ulu punguan. Makna dan fungsi dari ritual marari sabtu yaitu untuk memanjatkan doa 
kepada mula jadi nabolon agar di beri kesehatan, keselamatan, keamanan, dan kemakmuran. Setiap hari Sabtu atau Samisara seluruh umat Parmalim berkumpul di tempat yang sudah ditentukan baik si Bale Partonggoan, Bale Pasogit di pusat maupun di rumah parsantian di cabang/daerah untuk melakukan sembah dan puji kepada Mulajadi Nabolon dan pada kesempatan itu para anggota diberi poda atau bimbingan agar lebih tekun berprilaku menghayati Ugamonya.

\section{Daftar Pustaka}

Fitria, Vita. 2012. Interpretasi Budaya Clifford Geertz: Agama sebagai Sistem Budaya. Sosiologi Reflektif. 57-64

Gultom, Ibrahim. 2010. Agama Malim di Tanah Batak. Jakarta: Bumi Aksara. https://travel.kompas.com/read/2016/12/18/094728427/melongok.ibadah. marari.sabtu-nya.Parmalim

Moleong, Lexy L. 2007. Metode Penelitian Kualitatif. Bandung: PT Remaja Rosdakarya

Purba, Corry. 2015. Gerakan Politik dan Spritual Parmalim Dalam Rangka Mempertahankan. Studi Pendidikan Sejarah FKIP-USI 1-12

Siahaan, Debora. 2018. Kearifan Lokal Pada Upacara Sipahalima Masyarakat Parmalim Batak Toba. Universitas Sumatera Utara: Skripsi

Siregar, Vina Notriani. 2015. Pandangan Masyarakat Terhadap Parmalim di Desa Hutatinggi Kecamatan Laguboti Kabupaten Toba Samosir. Semarang

Situmorang, Nelita Br. 2017. Eksistensi Agama Lokal Parmalim, Studi Kasus di Nomonatif Pengahayat Nomor Punguan 35 Desa Air Kulim Mandau Bengkalis. JOM FISIP 1-15

Situmorang, Sitor, 1993. Guru Somalaing dan Modang Liani Utusan Raja Rom Jakarta, Grafindo Mukti

Sugiyono. 2012. Metode Penelitian. Jakarta: Alfabeta

Suharyanto, Agung. 2012. Makna Gondang dan Tort-tor dalam Upacara Ritual Parmalim Nasiak Bagi di Hutatinggi Laguboti Toba Samosir dalam Apresiasi Simbol dalam Seni Nusantara 1, 59-73, Bandung: CV. Bitang Warli Artika

Suharyanto, Agung. 2014. Tubuh Tari: Dimensi Sosial dan Transedental, Harian Analisa Medan, http://harian.analisadaily.com/rebana/news/dimensisosial-dan-transendental/83929/2014/11/23

Suharyanto, Agung. 2016. Pusat Aktivitas Ritual Ugamo Malim di Huta Tinggi Laguboti 
Wakhid, S, A. 2012. Dinamika Perkembangan Sistem Kepercayaan Lokal di Indonesia. Puslitbang Kehidupan Keagamaan Badan Litbang dan Diklat Kementerian Agama RI

Wiflihani \& Suharyanto, Agung. 2011. Upacara Sipaha Sada pada Agama Parmalim Di Masyarakat Batak Toba Dalam Kajian Semiotika, JUPIIS: Jurnal Pendidikan Ilmu-Ilmu Sosial, Vol 3 (1): 102-112

http://www.yopnik.com/toba/batak\%20nation.html

https://www.kaskus.co.id > Home Sumatera Utara . http://repository.usu.ac.id. (29 Januari 2015) 